\title{
Surface quality improvement of porous thin films suitable for nanoindentation
}

\author{
Zhangwei Chen*, Xin Wang, Finn Giuliani, Alan Atkinson \\ Department of Materials, Imperial College London SW7 2BP, UK \\ *Corresponding author: chen@ic.ac.uk (Z.Chen)
}

\begin{abstract}
The reliability of perovskite material $\mathrm{La}_{0.6} \mathrm{Sr}_{0.4} \mathrm{Co}_{0.2} \mathrm{Fe}_{0.8} \mathrm{O}_{3-\delta}(\mathrm{LSCF})$ to be used as cathode parts in solid oxide fuel cells (SOFCs)also relies on its mechanical properties. Adequate surface conditions (i.e. flat and crack-free) are desired when the as-sintered porous thin films are subjected to nanoindentation for mechanical property determination. In this study, extensive cracks and considerable surface roughness were found in the LSCF films after sintering at high temperatures. This would significantly scatter the nanoindentation data and result in unreliable measurements. Various attempts including the comparison of film deposition methods, drying and sintering processes, and reformulating the ink were made to improve the surface quality. Results revealed little dependence of cracking and surface roughness on deposition methods, drying or sintering processes. It was found that the critical factor for obtaining crackfree and smooth LSCF films was the ability of the ink to be self-levelling in the earlier wet state. Reproducible nanoindentation measurements were obtained for the films with improved surface quality.
\end{abstract}

\section{Keywords:}

Porous Thin Film; LSCF; Viscosity; Surface Defect; Cracking; Nanoindentation.

\section{Introduction}

Thanks to its excellent mixed electronic-ionic conductivity[1], perovskite material $\mathrm{La}_{0.6} \mathrm{Sr}_{0.4} \mathrm{Co}_{0.2} \mathrm{Fe}_{0.8} \mathrm{O}_{3-\delta}$ (LSCF) has been considered as a promising candidate to be used as cathode parts in intermediate temperature solid oxide fuel cells (IT-SOFCs)[2].Besides, an adequate porosity of approximately $30-40 \mathrm{vol} \%$ and a compatible thermal expansion coefficient matching with that of electrolytes are also desired along with a low cost and simple fabrication process[3, 4]. Currently most LSCF cathode films, often thin and porous, are fabricated by depositing (e.g. screen-printing)a few layers of commercial inks onto dense sintered electrolyte substrates, such as gadolinium doped ceria $\left(\mathrm{Ce}_{0.9} \mathrm{Gd}_{0.1} \mathrm{O}_{2-\delta}, \mathrm{CGO}\right)$, followed by high temperature sintering[3]. The knowledge of the mechanical properties of such cathode films is a prerequisite for the reliability and durability of the parts to be assessed for their application in rigorous environments where mechanical stresses arise.
Nanoindentation is an advantageous technique with high spatial and depth resolution that can be used to measure the mechanical properties (e.g. elastic modulus and hardness) of very small volumes of material, such as thin films of a few micrometers thickness[5, 6].There is currently no report on response of nanoindentation on porous thin LSCF films. In addition, in order that nanoindentation tests be reproducible and thus the results be reliable, cracking and surface asperities (i.e. agglomerates) in the as-sintered test films must be avoided or minimized to an acceptable level, which means the size of such defects should be much less comparable to the indented feature such as indentation depth, which in the current study wasless than $2 \mu \mathrm{m}$. However, as can be seen later in this paper, such defects were found constantly in the sintered LSCF films, which severely scattered the nanoindentation response and thus the resulting measurements were considered invalid.

Although such defects in the as-sintered LSCF films were also observed in some other studies, the 
problem has not yet been considered critical in many researches which essentially involved the study of electrochemical performance rather than mechanical properties of the SOFC component, as discussed later in Section 3. Due to the nature of the fabrication process and the application in SOFCs, the LSCF cathode films are difficult to be surface treated to obtain relatively flat surfaces, and the cracking remains a problem. As a result, the relevant technological challenges could be related to the fabrication of thin, porous, flat and crack-free LSCF cathode films.

To mitigate the cracking and surface asperity problems in LSCF cathode films, in the current study efforts were made in various aspects which involved the comparison of deposition methods, the improvement of drying and sintering processes, and of the ink formulation. Results revealed that a sufficiently low viscosity of the ink could result in crack-free LSCF films with flatter surfaces and a more homogeneous microstructure, while the alternative deposition method and the optimized thermal treatments applied helped little to solve the problems. In other words, the surface quality of the films was significantly improved by using a reformulated less viscous ink which ensured more ability to self-level in the early wet state upon deposition. By using these non-defective films, effective nanoindentation measurements were achieved with high reproducibility and hence reliable results were obtained.

\section{Methods and Materials}

Fully dense CGO pellet samples of approximately $25 \mathrm{~mm}$ in diameter and $3 \mathrm{~mm}$ thickwere prepared to be used as electrolyte substrates for LSCF film deposition by uniaxially pressing the powder (NexTech Materials, USA) at $150 \mathrm{MPa}$ pressure for 10 s. They were then isostatically pressed at 200 $\mathrm{MPa}$ for further compaction for $30 \mathrm{~s}$, followed by sintering at $1400{ }^{\circ} \mathrm{C}$ in air with a heating and cooling rate of $5{ }^{\circ} \mathrm{C} / \mathrm{min}$ and a holding time of 4 hours. The as-sintered dense substrates were polished on one face by successively using $15,9,6$, 4 and 1 micron diamond suspensions, to generate mirror smooth and flat surfaces.
An LSCF ink from ESL, UK was deposited first on the fully dense CGO substrates using either screen printing with 250 mesh screen and $2.5 \mathrm{~mm}$ gap or tape casting with a perimeter mask of $40 \mu \mathrm{m}$ height. The ready-made films were then oven-dried at $100{ }^{\circ} \mathrm{C}$ for 12 hours, followed by sintering in air at $1000{ }^{\circ} \mathrm{C}$ for 4 hours with a heating and cooling rate of $5{ }^{\circ} \mathrm{C} / \mathrm{min}$, according to the initial sintering program.

Reformulated inks were prepared respectively by diluting the as-supplied LSCF ink 1:1and 1:2by volume with terpineol (Sigma, UK) and then ballmilled for 12 hours to reach homogeneity. These two inks are noted as 1:1 ink and 1:2 ink in this study. The viscosity of the inks was measured by controlled-stress rheometer (CVO100D, Malvern Instruments Ltd, UK) at room temperature under shear rate of $95 \mathrm{~s}^{-1}$. The same deposition processes (i.e. screen printing and tape casting) were carried out for the reformulated inks to produce films for subsequent comparison experiments.

Thermogravimetric analysis (TGA) of the LSCF ink was performed in air in order to determine the thermal decomposition range. Dilatometry analysis on uniaxial-pressed green bodies of LSCF powders were carried out using a push-rod dilatometer DIL402C (NETZSCH, Germany) to investigate the sintering activity and shrinkage of the LSCF material. The experiment temperature range was set between room temperature and $1250{ }^{\circ} \mathrm{C}$, at four constant heating rates of $3,5,10$ and $20^{\circ} \mathrm{C} / \mathrm{min}$.

The microstructures of the dried and as-sintered films were studied using scanning electron microscopy (SEM) JEOL 5610 (JEOL, Japan), and the cross-sectional surfaces were preparedby fracture or focused ion beam (FIB) slice and view using Helios Nanolab (FEI, USA). The width of crack opening was also determined under SEM. The average surface roughness $\left(R_{a}\right)$ of the sintered LSCF films was measured using an optical interference surface profiler OMP-0360G (Zygo, USA).

Nanoindentation tests were performed under load control mode up to $500 \mathrm{mNon}$ a NanoTest platform (Micromaterials, UK) at room temperature using a spherical diamond tip of $50 \mu$ min diameter, with 1 $\mathrm{mN} / \mathrm{s}$ loading and unloading rate. Holding times of 2 seconds and 20 seconds were applied at peak 
load and at the end of unloading, respectively, to check for the creep effect and thermal drift. For each sample, a set of nanoindentation tests on at least 20 different locations on the surface were performed to obtain more representative average results. Before each test, calibration was made on a standard silica sample to establish the system frame compliance. The resulting nanoindentation response (i.e. load versus indentation depth curves) and the elastic modulus which was determined by applying Olive-Pharr method[5]based on the curves, were then used for the assessment of the reliability and reproducibility of the nanoindentation tests on the films.

\section{Results and Discussion}

\subsection{Defects in the as-sintered LSCF films}

In the preliminary study, severe cracking networks and a large number of surface asperities (i.e. agglomerates) were generated in the sintered films deposited by screen printing using the as-received ink. The surface and cross-sectional microstructures of a film after sintering at $1000{ }^{\circ} \mathrm{C}$ are shown in Fig. 1. The width of crack openings and the size of the agglomerated islands were measured to be $1-4 \mu$ mand $20-40 \mu \mathrm{m}$, respectively. It should be noted, however, that there was a good adhesion between the film and the substrate. Fig. 2 shows a magnified cross-section sliced by FIB, revealing vertical cracks penetrating through the film thickness and a dense agglomerate present under the film surface.
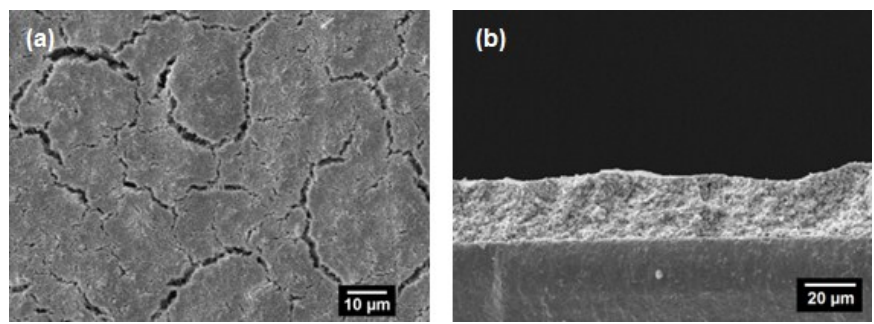

Fig. 1. SEM micrographs of a LSCF film after sintering at $1000^{\circ} \mathrm{C}$ : (a) top surface view of crack networks and agglomerates; (b) fracture crosssectional view of the poor surface smoothness

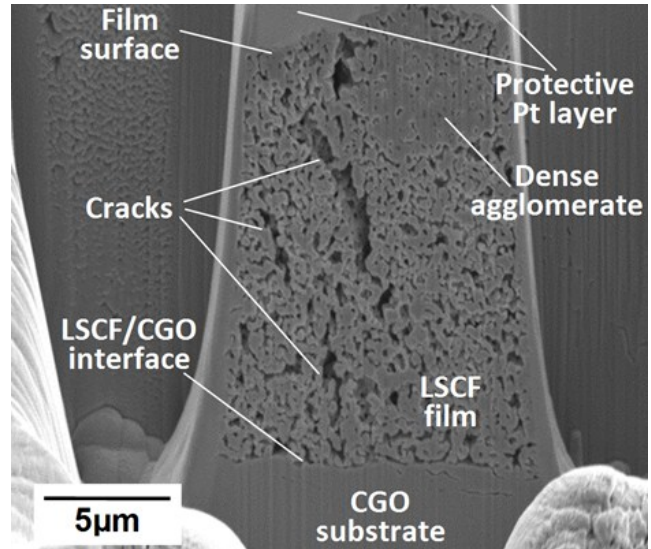

Fig. 2. FIB sliced cross-section showing cracks penetrating through the film and a large asperity near the surface of a film sintered at $900{ }^{\circ} \mathrm{C}$ for $4 \mathrm{~h}$

The fabrication of cathode components of SOFCs has been reported using various methods, such as screen printing, tape casting, dip casting, chemical vapor deposition, atmospheric plasma spray, colloidal spray deposition, pulsed-laser deposition, sputtering and painting, as reviewed by Fergus et al [3] and Taroco et al.[7]. In Table 1 we summarize the techniques reported to be used for the deposition of LSCF films on CGO substrates [8$13]$.

Table 1. Summary of observations from the literature on the deposition of LSCF films on CGO substrates.

\begin{tabular}{|c|c|c|c|c|c|}
\hline Reference & $\begin{array}{l}\text { Deposition } \\
\text { method }\end{array}$ & $\begin{array}{l}\text { Heat treatment } \\
\text { conditions }\end{array}$ & $\begin{array}{l}\text { Film } \\
\text { thickness } \\
(\mu \mathrm{m})\end{array}$ & $\begin{array}{l}\text { Crack } \\
\text { opening } \\
\text { width } \\
(\mu \mathrm{m}) \\
\end{array}$ & $\begin{array}{l}\text { Surface } \\
\text { asperities }\end{array}$ \\
\hline $\begin{array}{l}\text { Lee et al. } \\
{[8]}\end{array}$ & Screen printing & $\begin{array}{l}\text { Sintering at } \\
1000^{\circ} \mathrm{C} \text { for } 0.5 \mathrm{~h}\end{array}$ & $<40$ & $<30$ & Yes \\
\hline $\begin{array}{l}\text { Baque et } \\
\text { al. [9] }\end{array}$ & Dip coating & $\begin{array}{l}\text { Dried at } 130{ }^{\circ} \mathrm{C} \text {; } \\
\text { Sintering at } 900 \\
{ }^{\circ} \mathrm{C} \text { for } 6 \mathrm{~h}\end{array}$ & $<28$ & $<20$ & Yes \\
\hline $\begin{array}{l}\text { Marinha } \\
\text { et al. [10] }\end{array}$ & $\begin{array}{l}\text { Electrostatic } \\
\text { spray } \\
\text { deposition } \\
\text { (ESD) }\end{array}$ & $\begin{array}{l}\text { Substrate } \\
\text { temperature } \\
250-450{ }^{\circ} \mathrm{C} ; \\
\text { Sintering at } 900 \\
{ }^{\circ} \mathrm{C} \text { for } 2 \mathrm{~h}\end{array}$ & $<25$ & $<5$ & Yes \\
\hline $\begin{array}{l}\text { Hsu et al. } \\
{[11]}\end{array}$ & $\begin{array}{l}\text { Electrostatic- } \\
\text { assisted } \\
\text { ultrasonic } \\
\text { spray pyrolysis } \\
\text { (EAUSP) }\end{array}$ & $\begin{array}{l}\text { Deposition } \\
\text { temperature } 350 \\
{ }^{\circ} \mathrm{C} \text {; Sintering at } \\
1000^{\circ} \mathrm{C} \text { for } 2 \mathrm{~h}\end{array}$ & -- & $<2$ & Yes \\
\hline $\begin{array}{l}\text { Santillan } \\
\text { et al. [12] }\end{array}$ & $\begin{array}{l}\text { Electrophoretic } \\
\text { deposition } \\
\text { (EPD) }\end{array}$ & $\begin{array}{l}\text { Sintering at } \\
950^{\circ} \mathrm{C} \text { in air for } \\
2 \mathrm{~h} \\
\end{array}$ & $<25$ & $\begin{array}{l}\text { No } \\
\text { detectable } \\
\text { crack }\end{array}$ & Yes \\
\hline $\begin{array}{l}\text { Wang et } \\
\text { al. [13] }\end{array}$ & $\begin{array}{l}\text { In-situ solid- } \\
\text { state reaction } \\
\text { sintering }\end{array}$ & $\begin{array}{l}\text { Sintering at } \\
1000^{\circ} \mathrm{C} \text { in air } \\
\text { for } 6 \mathrm{~h}\end{array}$ & -- & $\begin{array}{l}\text { No } \\
\text { detectable } \\
\text { crack }\end{array}$ & Yes \\
\hline
\end{tabular}

${ }^{\mathrm{a}} \mathrm{La}_{0.4} \mathrm{Sr}_{0.6} \mathrm{Co}_{0.8} \mathrm{Fe}_{0.2} \mathrm{O}_{3-\delta}$ was used as film material in this case. 
From the literature listed above, it can be concluded that most LSCF films possessed more or less cracking and surface asperities after final heat treatments, irrespective of the deposition method applied. Although no detectable cracking was present in the films for [12] and [13], the surface asperities remain a great concern when it comes to undertaking nanoindentation tests.

Adjusting working parameters may to some extent reduce film cracking, but these deposition methods still struggle with preparing crack-free and flat LSCF films containing highly porous structures. This implies that the existence of cracking is prevalent in many LSCF films irrespective of their deposition techniques. Therefore, the challenge remains to be the fabrication of crack-free and flat LSCF films. Although many have observed such defects in their LSCF films, they often attributed them to the densification and shrinkage of films during sintering, or the TEC mismatch between films and substrates during cooling, without any further experimental validation [8, 11], Although these defects might not be of major importance for studies on electrochemical performance, they are, however, crucial for the present study, as their presence in the films would certainly cause errors in the nanoindentation response. Furthermore they are likely to induce damage to cells in actual application.

\subsection{Nanoindentation response on defective LSCF films}

Nanoindentation on the film shown in Fig.1 was conducted and the response curves, namely the load vs. indentation depth curves, generated are shown in Fig.3.

The extremely irregular shapes and wide variability of the response curves seen in the figure were generated by the indenter tip touching defective locations on the films during nanoindentation tests. The presence of cracks and poor surface flatness due to large asperities induced significant variability in the measured elastic modulus values. In the current case, in addition to the extensive cracks, it was found that the average surface roughness $R_{a}$ for the defective film was measured to be $1.86 \mu \mathrm{m}$, which was very close to the indentation depth of approximately $2 \mu \mathrm{m}$, resulting in an enormous relative error as much as $63.2 \%$ for the apparent elastic modulus $(34 \pm 21 \mathrm{GPa})$, as shown in Fig. 3(b).
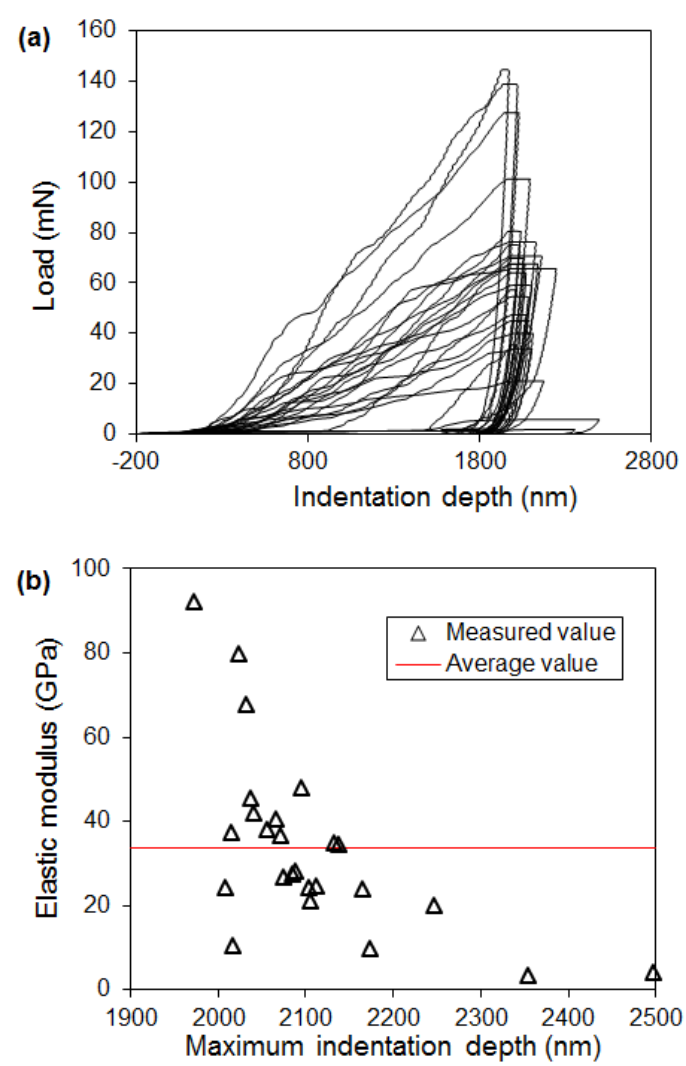

Fig. 3. Nanoindentation load vs. indentation depth curves (a) and the corresponding elastic modulus values calculated (b) for the defective films similar to those in Figures 1 and 2.

Examples of three typical nanoindentation loaddepth curves collected in this study are plotted in Fig. 4, which demonstrate the existence of three different contact processes of the indenter tip with the sample surface and are related to the characteristic surface features described earlier.

Curve-1 is typical of a relatively smooth and uncracked surface location, it being less influenced by these defects. However, there is still an irregular response during loading (such as the "pop-in" events, as indicated by arrows) which is attributed to the fact that the LSCF film was not smooth enough. In contrast, curve- 2 and curve-3 show extremely unreliable responses. Curve- 2 exhibits a deep "pop-in" attributable to the cracks in the contact location. The existence of the initial negative depth in curve- 3 indicates that during 
loading an asperity on the indent surface was first touched by the tip.
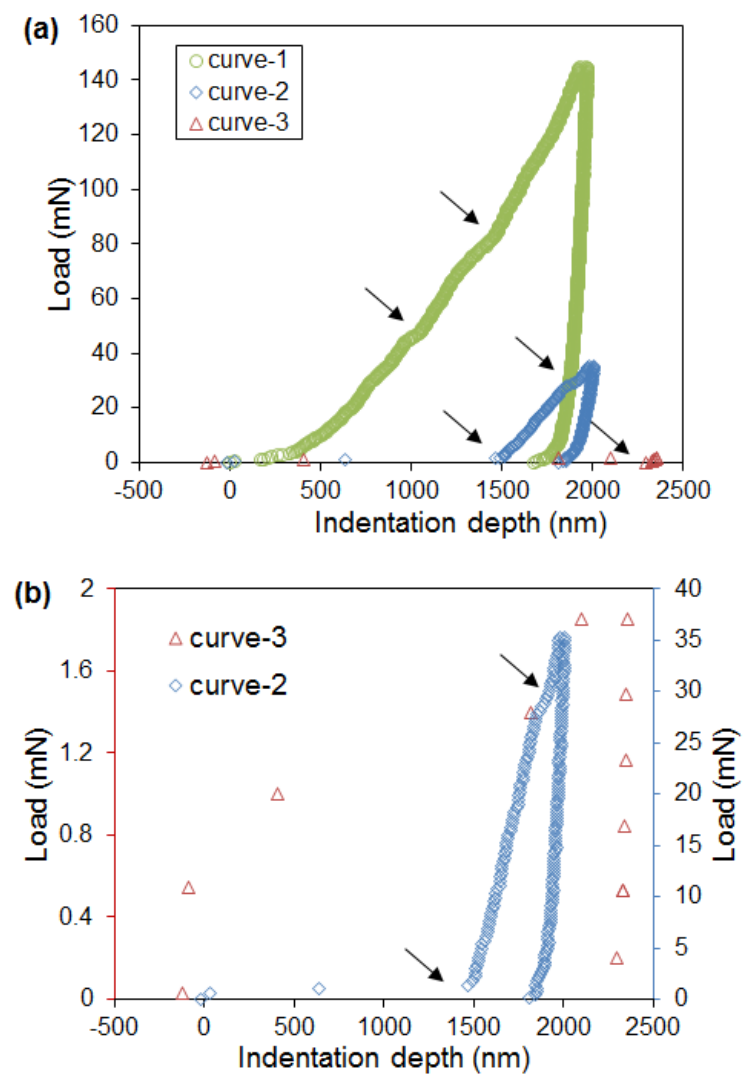

Fig. 4. Examples of load-depth curves for nanoindentation using spherical indenter tip corresponding to likely features at the indent locations. (b) plots curve-2 and curve-3 on an expanded load scale.

For a spherical indenter tip, the characteristic surface roughness of the test sample must be negligible compared to the maximum indentation depth. While for a Berkovich or other types of sharp tip, the indentation results are much more sensitive to the surface quality and porous microstructures. This was also the reason that in this work a spherical indenter tip was used for nanoindentation, particularly on porous LSCF films of which the surface was hard to polish.

\subsection{Improvement of LSCF film surface quality}

Given the analysis above, it was imperative that the cracking and surface asperities be reduced for the properties of the LSCF films to be reliably and reproducibly measured using nanoindentation. As the aim of this study, the improvement of the film surface quality required the investigation of the possible influencing factors of the defect formation, such as the TEC mismatch between LSCF films and CGO substrates, the drying, sintering and cooling processes applied, the deposition methods used as well as the formulation of the ink, which will be discussed below in more detail.

\subsubsection{TEC mismatch between LSCF films and CGO substrates}

One reason that LSCF is a promising cathode material is because its TEC $\left(15.3 \times 10^{-6} \mathrm{~K}^{-1}, 100\right.$ $\left.600{ }^{\circ} \mathrm{C}\right)[2]$ is close to that of CGO $\left(13.5 \times 10^{-6} \mathrm{~K}^{-1}\right)$ [14], which means there exists only a small thermal expansion mismatch. Nevertheless, even this small difference would induce a tensile thermal stress which would facilitate crack formation in the film during cooling after sintering. To avoid this possible effect caused by TEC mismatch, some dense substrates were prepared with the same material (i.e. LSCF) as the films by sintering at $1200^{\circ} \mathrm{C}$ for 4 hours with a heating rate of $300^{\circ} \mathrm{C} / \mathrm{h}$. The LSCF film was applied by screen printing the as-received ink and the resulting sample was then sintered under the same condition as the previous samples on CGO substrates. This would certainly exclude the crack formation caused by the TEC mismatch between films and substrates. From Fig.5, which shows SEM microstructures of the sintered LSCF film, it can be seen that the film surface was full of asperities.
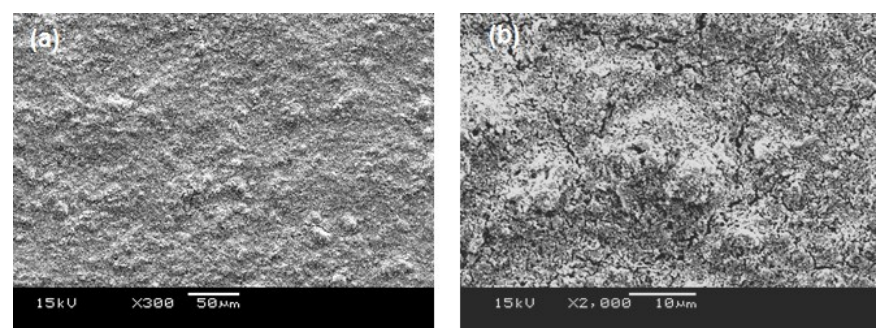

Fig. 5. SEM images of sintered LSCF films screen printed on LSCF substrates. Images (a) and (b) are shown at different magnifications

Again, a cracking network was observed on the surface with crack openings of $1.5 \mu \mathrm{m}$ wide. Hence little dependence was shown of the cracking on the thermal expansion coefficient difference between LSCF and substrate materials since cracking still 
occurred for LSCF films on LSCF substrates, which involved zero TEC difference.

\subsubsection{Drying, sintering and cooling processes}

Cracking could also be attributed to the shrinkage of the films themselves during the drying and constrained sintering processes. Therefore, an investigation of the influence of thermal treatments on defect formation was carried out.

\subsubsection{TG-DSC analysis}

Thermogravimetric analysis (TGA) of the commercial LSCF ink was performed in air atmosphere in order to determine the thermal decomposition range of the organic constituents. Fig. 6 shows the TG-DSC curves of the ink at a heating rate of $10^{\circ} \mathrm{C} / \mathrm{min}$.

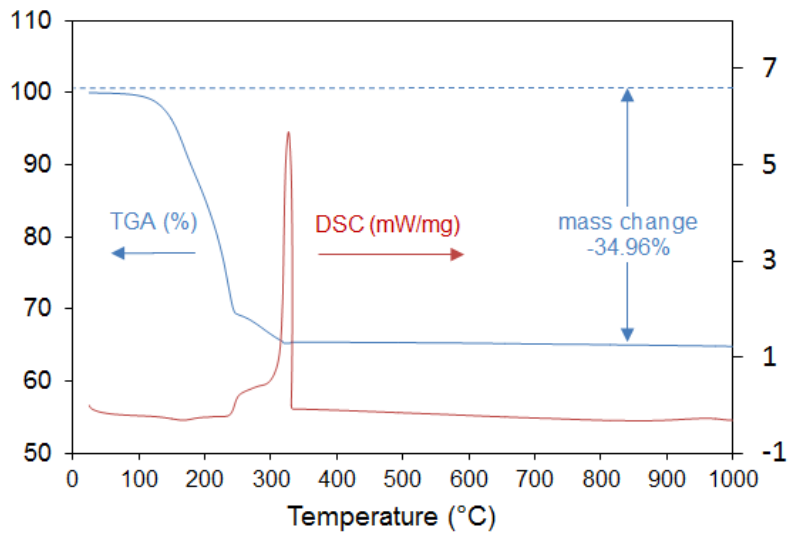

Fig. 6. TG and DSC curves of the as-received LSCF ink in air atmosphere.

As can be seen from the TG curve, the thermal decomposition of the ink underwent three steps: the volatile organic solvent started volatilization at around $\quad 100 \quad{ }^{\circ} \mathrm{C}, \quad$ followed by oxidation/decomposition of a majority of organic content when the temperature increased to $220{ }^{\circ} \mathrm{C}$, resulting in a major mass loss. The organic residues continued to be burnt-out until the temperature reached $320{ }^{\circ} \mathrm{C}$, after which the weight remained almost constant.(The oxygen desorption from the LSCF perovskite lattice with increasing temperature[15] was too small to be observable on this scale.) The decomposition completed with a total mass loss of $34.96 \%$.

\subsubsection{Dilatometry}

Dilatometry measurements on uniaxial-pressed green bodies of LSCF powder were performed to investigate the sintering activity and shrinkage of the LSCF powder. The heating dilatometric curves are shown in Fig. 7 at four constant heating rates: i.e. $3,5,10,20{ }^{\circ} \mathrm{C} / \mathrm{min}$ from room temperature to $1250{ }^{\circ} \mathrm{C}$.

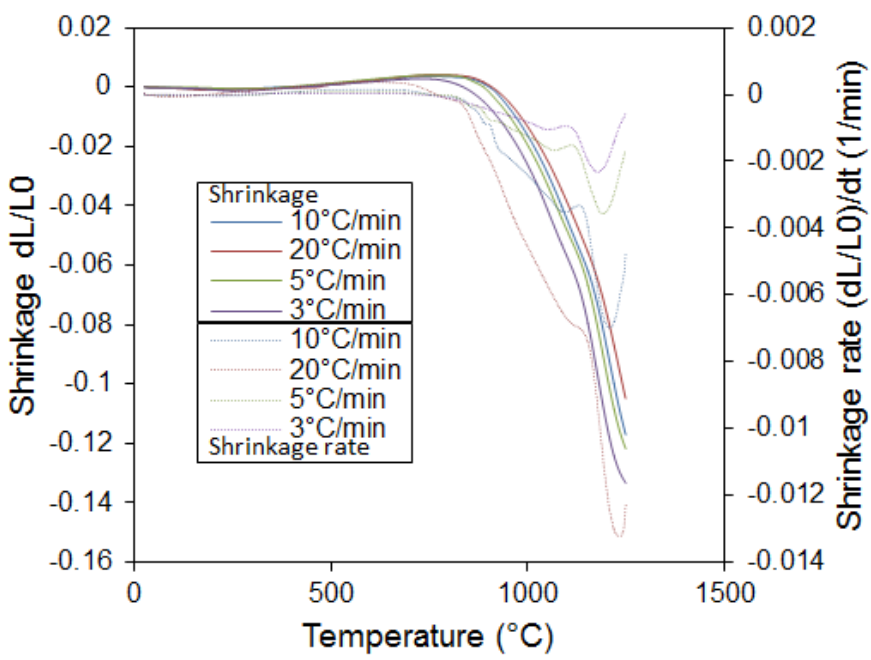

Fig. 7. Shrinkage and shrinkage rate vs. temperature during constant heating rate sintering of LSCF at 3, 5, 10, $20^{\circ} \mathrm{C} / \mathrm{min}$ heating rates

No significant dimensional changes were observed up to $500{ }^{\circ} \mathrm{C}$, after which thermal expansion was observable until noticeable shrinkage phenomena began at around $800{ }^{\circ} \mathrm{C}$. The densification process continued steeply up to $1250{ }^{\circ} \mathrm{C}$. The final shrinkage ranged from $10 \%$ at a $20{ }^{\circ} \mathrm{C} / \mathrm{min}$ heating rate to $14 \%$ at a $3{ }^{\circ} \mathrm{C} / \mathrm{min}$ heating rate, suggesting that smaller heating rates allowed more sufficient time for shrinkage which resulted in higher degree of densification. The shrinkage rate $(\mathrm{dL} / \mathrm{dt})$ depended on the heating rate applied. For example, above $1000{ }^{\circ} \mathrm{C}$ the shrinkage rate for a $20{ }^{\circ} \mathrm{C} / \mathrm{min}$ heating rate was several times greater than that for a heating rate of $3{ }^{\circ} \mathrm{C} / \mathrm{min}$, indicating that a film would be more likely to crack when sintered at a $20{ }^{\circ} \mathrm{C} / \mathrm{min}$ heating rate.

An excellent sintering activity was found for the LSCF powder used in the present study. This was due to its high specific surface area and relatively homogeneous particle size distribution. The shrinkage rate reached a maximum at 
approximately $1200{ }^{\circ} \mathrm{C}$. Considering a porosity of approximately $35 \mathrm{vol} \%$ was required for a cathode film, an appropriate sintering temperature for the LSCF films should fall in the range $800-1000{ }^{\circ} \mathrm{C}$.

\subsubsection{Modified sintering programs}

If the cracks were generated by the constrained shrinkage of the films, then it was considered that the cracking problem might be avoided by optimizing the burn-out and sintering schedule based on the thermal analyses described above. The sintering program was therefore modified as follows: for the organics removal step between room temperatureand $350{ }^{\circ} \mathrm{C}$, a very slow heating rate was employed $\left(3{ }^{\circ} \mathrm{C} / \mathrm{min}\right.$ or $1{ }^{\circ} \mathrm{C} / \mathrm{min}$, holding for 2 hours at $350{ }^{\circ} \mathrm{C}$ ); for the stable period between 350 and $800{ }^{\circ} \mathrm{Ca}$ medium heating rate was used $\left(5^{\circ} \mathrm{C} / \mathrm{min}\right)$ and a holding time was applied at $800{ }^{\circ} \mathrm{C}(4$ hours $)$ at the start of sintering to strengthen the particle network; between 800 and the target maximum sintering temperature a much lower heating rate was used $\left(1^{\circ} \mathrm{C} / \mathrm{min}\right)$ and a much longer holding time (48 hours) was used at the top temperature; finally cooling to room temperature was done at $5{ }^{\circ} \mathrm{C} / \mathrm{min}$. For the particular case of a top temperature of $1000{ }^{\circ} \mathrm{C}$, the sintering program is plotted in Fig.8, compared with the initial sintering schedule.

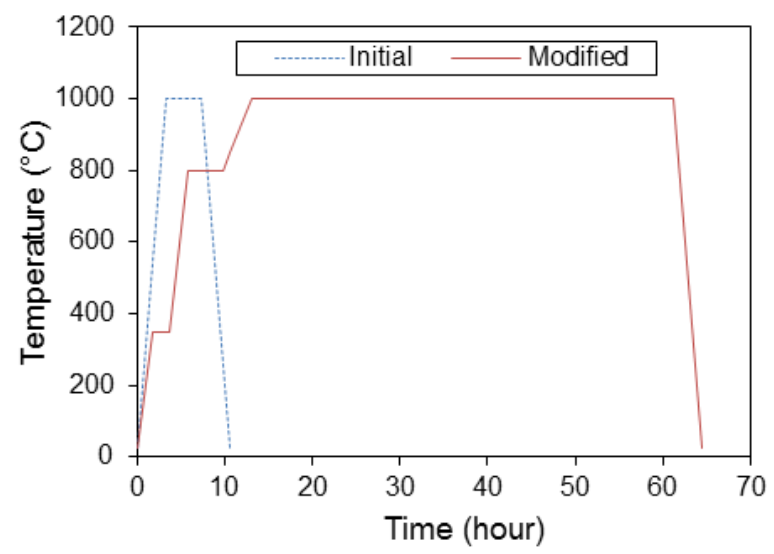

Fig. 8. Comparison of the initial and modified sintering programs.

The micrograph of the sintered film using the modified sintering program is shown in Fig.9. Unfortunately this shows little improvement of surface quality compared to that using the initial sintering program. There are still many cracks up to $1.5 \mu \mathrm{m}$ wide and asperities at least $10 \mu \mathrm{m}$ in diameter showing little effectiveness of the modified sintering conditions.

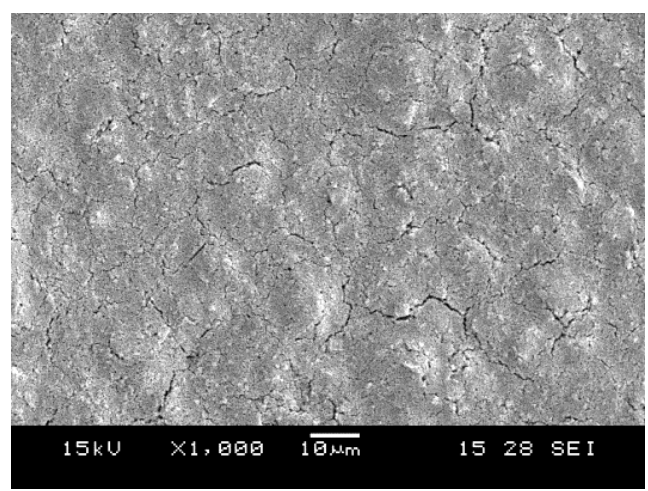

Fig. 9. Micrograph of the surface features of a film sintered with the modified sintering program.

Other sintering programs were also explored to see if they could prevent the cracking. Fig. 10 are the top surface micrographs of LSCF films sintered using these alternative sintering programs: 1) Sintering temperature $900{ }^{\circ} \mathrm{C}$, holding for $4 \mathrm{~h}$, extremely slow heating rate of $5^{\circ} \mathrm{C} / \mathrm{h}$ between 800 $900^{\circ} \mathrm{C}$, heating and cooling rate $5{ }^{\circ} \mathrm{C} / \mathrm{min}$ for other segments; 2) Sintering temperature $800^{\circ} \mathrm{C}$, holding for $4 \mathrm{~h}$, extremely slow heating rate $3{ }^{\circ} \mathrm{C} / \mathrm{h}$ between $700-800{ }^{\circ} \mathrm{C}$, heating and cooling rate $5{ }^{\circ} \mathrm{C} / \mathrm{min}$ for other segments; 3) Sintering temperature: 800C, holding for $20 \mathrm{~h}$, heating and cooling rate $6{ }^{\circ} \mathrm{C} / \mathrm{h}$.

Extensive cracks and asperitiescould still be found in all sintered films in the above experiments, indicating that the prevention of cracking was not achieved by lowering sintering temperatures or slowing down heating/cooling rates. This also implies that cracking in the films does not originate in the sintering process. However, the results do showthat a lower sintering temperature results in a smaller crack opening width. Fig. 11 shows the cracks in LSCF films after sintering at 1100 and $1200{ }^{\circ} \mathrm{C}$. Compared with the film sintered at $1000{ }^{\circ} \mathrm{C}$, the crack opening width increased to 6 and $10 \mu \mathrm{m}$, respectively, resulting in islands of approximately $30 \mu \mathrm{m}$ diameter on the surface.

Our recent study [16] of the formation in $8 \mathrm{~mol} \%$ yttria stabilized zirconia (8YSZ) films showed that cracks already present in the dried films cannot be healed during constrained sintering. which 
suggested that cracks found after sintering are probably initiated during the drying stage.
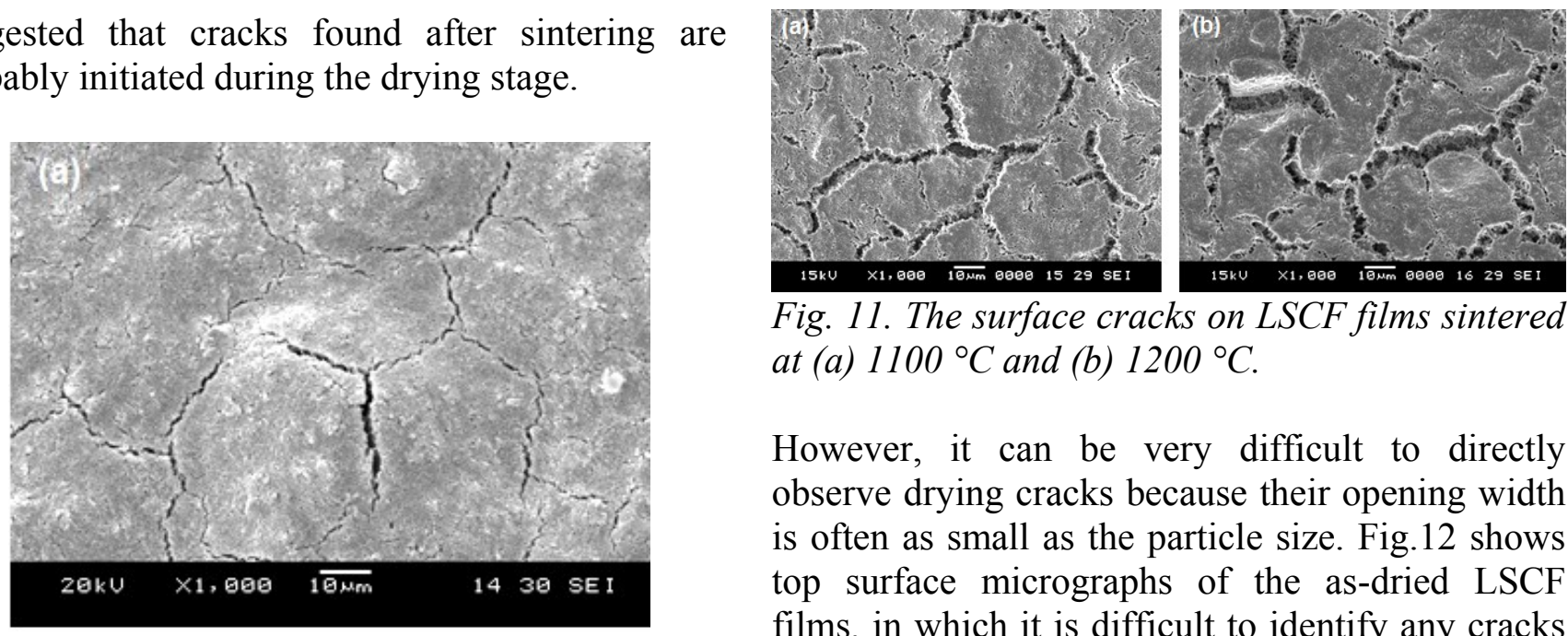

Fig. 11. The surface cracks on LSCF films sintered at (a) $1100^{\circ} \mathrm{C}$ and (b) $1200^{\circ} \mathrm{C}$.

However, it can be very difficult to directly observe drying cracks because their opening width is often as small as the particle size. Fig. 12 shows top surface micrographs of the as-dried LSCF films, in which it is difficult to identify any cracks with certainty, although typical asperities, probably

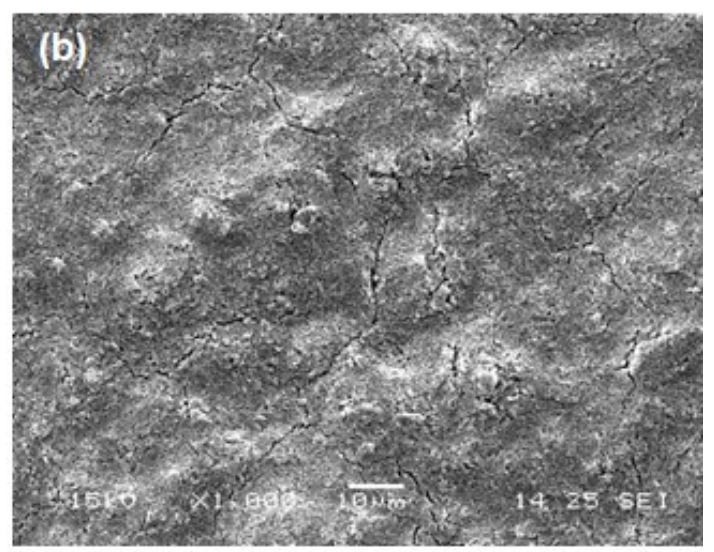
due to inhomogeneous packing of particles, are evident at this early stage.
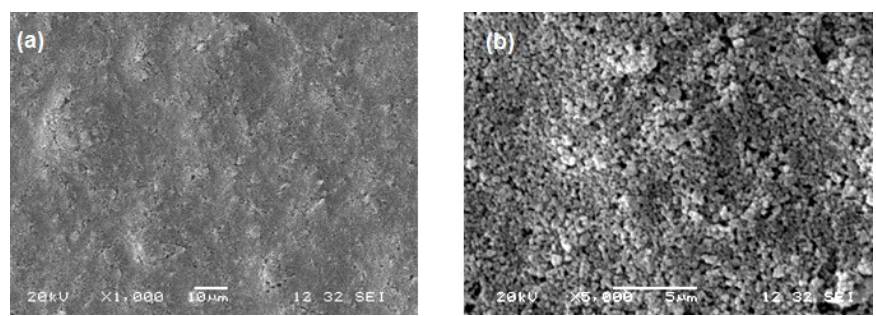

Fig. 12. Micrographs of dried LSCF films screen printed on $C G O$ substrates. Images (a) and (b) are shown at different magnifications.

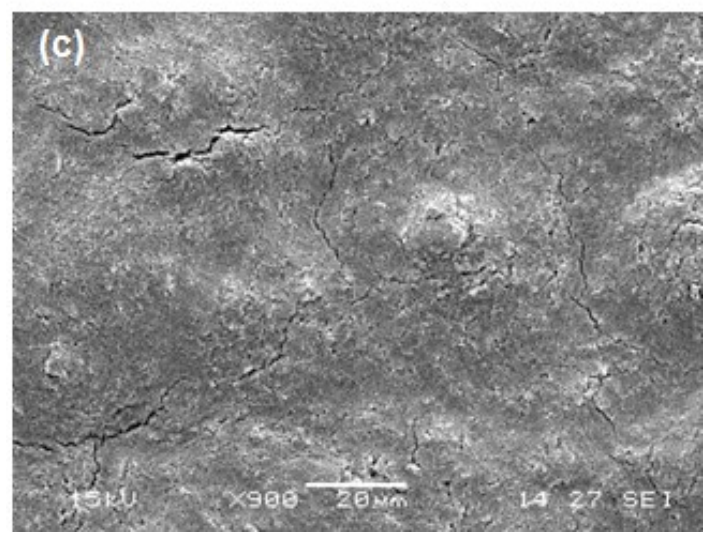

Fig. 10. Micrographs of LSCF film top surfaces after different sintering schedules. (a): Sintering temperature $900{ }^{\circ} \mathrm{C}$, holding for $4 \mathrm{~h}$, slow heating rate of $5{ }^{\circ} \mathrm{C} / \mathrm{h}$ between $800-900{ }^{\circ} \mathrm{C}$, heating and cooling rate $5{ }^{\circ} \mathrm{C} / \mathrm{min}$ for other segments; (b) Sintering temperature $800^{\circ} \mathrm{C}$, holding for $4 \mathrm{~h}$, slow heating rate $3{ }^{\circ} \mathrm{C} / \mathrm{h}$ between $700-800{ }^{\circ} \mathrm{C}$, heating and cooling rate $5{ }^{\circ} \mathrm{C} / \mathrm{min}$ for other segments; (c) Sintering temperature: 800C, holding for 20h, heating and cooling rate $6^{\circ} \mathrm{C} / \mathrm{h}$

\subsubsection{Film deposition methods}

Considering that the non-uniform pressure distribution due to the wire mesh of the screen printer could be a reason for the presence of cracking and surface asperities, we investigated an alternative deposition method to deposit the ink, i.e. casting with a doctor blade. The CGO pellet was partially covered by a perimeter mask of a controlled thickness and a doctor blade coated with LSCF ink was pressed under constant pressure and swept smoothly across the pellet surface by hand. Drying and sintering programs, which were identical to the ones used for the screen-printed samples in the beginning of the study, were applied. The SEM micrographs of the sample surface after sintering are shown in Fig. 13. The surface is smoother and has finer cracks although the network remained visible. It is speculated that tape casting eased the homogeneous packing of the 
particles in the ink after deposition, so the presence of agglomerates was reduced, resulting in a flatter film surface, but the cracking was not prevented, although reduced in severity.
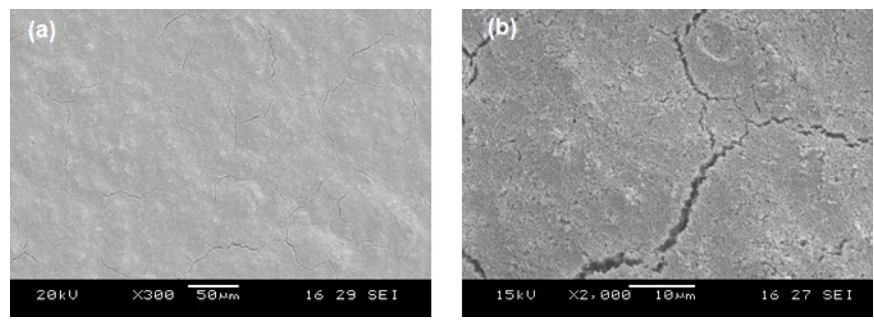

Fig. 13. Micrographs of sintered LSCF films fabricated by tape casting. Images (a) and (b) are shown at different magnifications.

\subsubsection{Ink formulation}

In the light of the above experiments, the wetting of the ink and the dynamic interaction of the particles in the ink, which were largely controlled by the ink viscosity, were thought to play an important role in the packing of the particles in the films after deposition and subsequent drying and sintering. Therefore, reformulated inks were prepared as described in Section 2 and deposited on CGO substrates by tape casting. The initial drying and 3-step sintering programs were applied to sinter the as-deposited films at $1000^{\circ} \mathrm{C}$. The surface and fracture cross-sectional morphology of these two films were examined under SEM, as shown in Fig. 14.
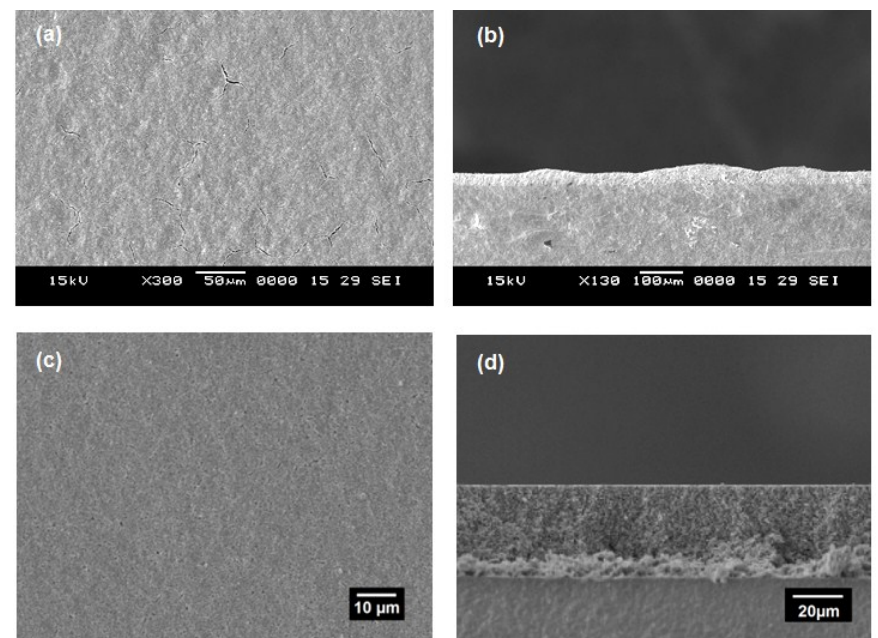

Fig. 14. Micrographs of top surfaces and fracture cross-sections of as-sintered LSCF films made by tape casting reformulated inks: $(a, b): 1: 1$ diluted ink; $(c, d): 1: 2$ diluted ink.

Compared with films (Fig. 1) made from the asreceived ink, Fig. 16 shows a drastic decrease on the number of cracks and surface agglomerates. Some fine cracks and surface asperities could still be observed in the film made from the 1:1 diluted ink, whereas for the film made from 1:2 diluted ink, cracks are not seen and the film maintained a very flat surface. A more detailed observation using FIB cross sectioning and SEM (Fig. 15) shows that the cracks were completely eliminated in the latter film, showing that by using the $1: 2$ diluted ink acceptable non-defective films could be fabricated. It is worth noticing that compared with the microstructure shown in Figures 1 and 2 for the films made from the original ink, Figures 14 (c), (d) and 15 demonstrate a much more homogeneously interconnected microstructure for the films made from 1:2 diluted ink, and have benefitted from the lower ink viscosity.
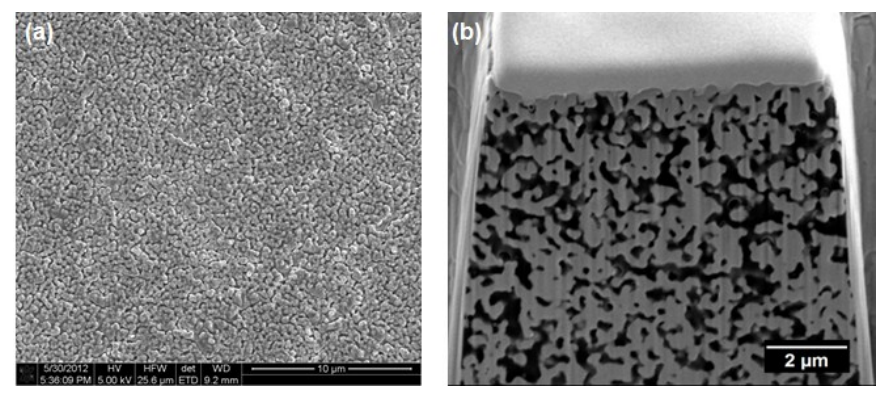

Fig. 15. (a) High magnification surface and (b) FIB sliced cross-sectional micrographs of a film made from the 1:2 diluted ink after sintering at $1000{ }^{\circ} \mathrm{C}$. Note that the dark phase in (b) is epoxy resin impregnated prior to FIB slicing

Nanoindentation tests were performed subsequently on this crack-free and flat film, the response curves and the resulting elastic modulus are plotted in Fig.16 (a) and (b), respectively. The results above show that the measurements for the non-defective film were significantly less scattered than for the defective one (Fig. 3), as the unloading response curves plotted in Fig. 16(a), from which the elastic modulus was determined, were highly consistent. Table 2 compares the properties of the 
as-receivedink and the diluted inks as well as the characteristics of the films fabricated from them.
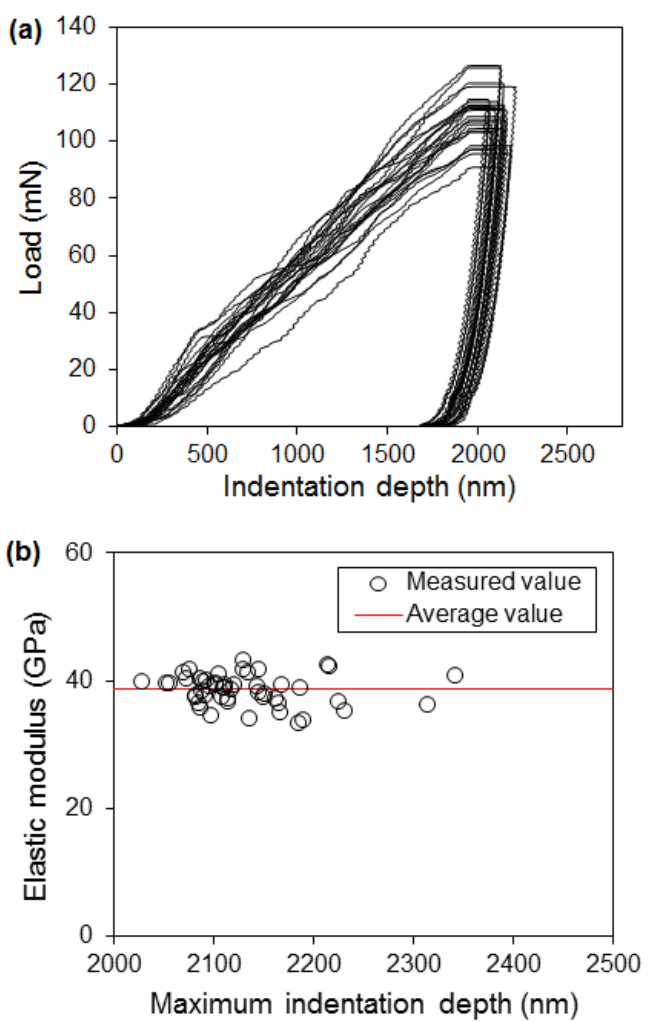

Fig. 16. (a) Nanoindentation load vs. indentation depth curves and (b) the corresponding elastic modulus values calculated for the crack-free and flat film made from 1:2 diluted ink.

Table 2 Comparison between properties of the asreceived and diluted inks and their corresponding films sintered at $1000^{\circ} \mathrm{C}$.

\begin{tabular}{cccc}
\hline Properties & $\begin{array}{c}\text { Original } \\
\text { ink }\end{array}$ & $1: 1$ ink & $1: 2$ ink \\
\hline Viscosity $($ Pa.s $)$ & 41.51 & 12.36 & 7.19 \\
\cline { 2 - 4 } & \multicolumn{3}{c}{ Corresponding films fabricated } \\
\hline $\begin{array}{c}\text { Average surface } \\
\text { roughness } R_{a} \\
(\mu m)\end{array}$ & 1.82 & 0.89 & 0.20 \\
$\begin{array}{c}\text { Elastic modulus } \\
(G P a)\end{array}$ & $33.7 \pm 21.3$ & $35.4 \pm 10.8$ & $38.6 \pm 2.4$ \\
\hline
\end{tabular}

Lower ink viscosities resulted in remarkable decreaseof surface roughness andstandard deviation of elastic modulus, implying a significantly reducednumber of surface defects in the corresponding films. As can be seen in Table 2, the surface roughness for the films made from 1:2 ink was reduced to merely $10 \%$ that of films made from the as-receivedink.This is much smaller than the indentation depth, resulting in a steep reductionin the relative standard deviationofmeasured elastic modulus from $63.2 \%$ to $6.2 \%$.

The experiments above revealed that rather than shrinkage during sintering, or differential contraction during cooling as proposed in many studies[11, 17], the more critical factor for obtaining crack-free and flat films in the current study was the ability of the ink to be self-leveling in the early wet state. Cracking is most likely to initiate at the drying stage if the particles are prevented from packing more effectively as the liquid content was removed. Lowering ink viscosity, by adding more terpineol solvent in this case, could effectively keep the ceramic particles in a stable suspension in the ink and flocculated agglomerates could be avoided. It also promoted the dispersion of the particles in a more homogeneous way as revealed by Maiti and Rajender [18]. As a result, cracking and asperity formation could be reduced to an acceptable level, or even be completely avoided. Consistent and reliable nanoindentation measurements could thus be conducted with higher reproducibility.

\section{Conclusions}

In summary, we have shown that sintered porous thin LSCF SOFC cathode films fabricated using a typical screen-printing ink were full of cracks and surface asperities, which caused extreme inconsistency and errors in attempts to measure film elastic modulus by nanoindentation. Various processing parameters were investigated in order to eliminate these defects. Different film deposition methods and thermal treatments showed little effect on the prevention of the defect formation. Furthermore the cracks were shown not to arise from thermal expansion mismatch between film and substrate and it was concluded that the defects initiated during drying of the ink and then made more severe by the sintering process. Thus, sintered porous thin LSCF cathode films were successfully fabricated without any crack or 
surface asperities by using a much less viscous ink. Results suggested that adequate amount of terpineol solvent added in the commercial ink eased the wetting and self-leveling of the ink upon deposition and thus a more homogeneous packing of LSCF particles in the films was achieved. As a result there was more homogeneous shrinkage in the film during the thermal treatments followed and lower local stresses in the films. With the nondefective films, consistent and reliable elastic modulus values of the films could then be obtained using nanoindentation.

\section{Acknowledgement}

This research was carried out as part of the UK Supergen consortium project on "Fuel Cells: Powering a Greener Future". The Energy Programme is an RCUK cross-council initiative led by EPSRC and contributed to by ESRC, NERC, BBSRC and STFC. Z. Chen is especially grateful to the Chinese Government and Imperial College for financial support in the form of scholarships. Thanks are additionally due to Dr. Vineet Bhakhri for assistance with nanoindentation.

\section{References}

1. Teraoka Y, Zhang HM, Okamoto K, Yamazoe N: Mixed ionic-electronic conductivity of La1-xSrxCo1-yFeyO3- $\delta$ perovskite-type oxides. Materials Research Bulletin 1988, 23(1):51-58.

2. Tai LW, Nasrallah MM, Anderson HU, Sparlin DM, Sehlin SR: Structure and Electrical Properties of La1-xSrxCo1yFeyO3. Part 2: The System La1xSrxCo0.2Fe0.803. Solid State Ionics 1995(76):273-283.

3. Fergus JW: Solid oxide fuel cells: materials properties and performance, vol. 1: CRC PressI Llc; 2009.

4. Singhal S: High-temperature Solid Oxide Fuel Cells: Fundamentals, Design and Applications: Fundamentals, Design and Applications: Elsevier Science; 2003.

5. Oliver WC, Pharr GM: An improved technique for determining hardness and elastic modulus using load and displacement sensing indentation experiments. Journal of Materials Research 1992, 7(6):1564-1583.

6. Oliver WC: Measurement of hardness and elastic modulus by instrumented indentation: Advances in understanding and refinements to methodology. Journal of Materials Research 2004, 19(1):3.

7. Taroco H, Santos J, Domingues R, Matencio T: Ceramic Materials for Solid Oxide Fuel Cells. 2011.

8. Lee S, Chu C-L, Tsai M-J, Lee J: High temperature oxidation behavior of interconnect coated with LSCF and LSM for solid oxide fuel cell by screen printing. Applied Surface Science 2010, 256(6):1817-1824.

9. Baque L, Serquis A: Microstructural characterization of La0.4Sr0.6Co0.8Fe0.2O3- $\delta$ films deposited by dip coating. Applied Surface Science 2007, 254(1):213-218.

10. Marinha D, Dessemond L, Cronin JS, Wilson JR, Barnett SA, Djurado E: Microstructural 3D Reconstruction and Performance Evaluation of LSCF Cathodes Obtained by Electrostatic Spray Deposition. Chemistry of Materials 2011, 23(24):5340-5348.

11. Hsu C-S, Hwang B-H: Microstructure and Properties of the La0.6Sr0.4Co0.2Fe0.8O3- $\delta$ Cathodes Prepared by Electrostatic-Assisted Ultrasonic Spray Pyrolysis Method. Journal of The Electrochemical Society 2006, 153(8):A1478-A1483.

12. Santillán MJ, Caneiro A, Quaranta N, Boccaccini AR: Electrophoretic deposition of $\mathrm{La0.6Sr0.4Co0.8Fe0.2O3- \delta}$ cathodes on $\mathrm{Ce0.9Gd0.101.95}$ substrates for intermediate temperature solid oxide fuel cell (IT-SOFC). Journal of the European Ceramic Society 2009, 29(6):1125-1132.

13. Wang S, Awanob M, Matsuda K, Maeda K: Porous La0.6Sr0.4Co0.2Fe0.8O2.8 electrodes prepared by in-situ solid-state reaction sintering. In: Power Sources for 
the New Millennium: Proceedings of the International Symposium: 2001. The Electrochemical Society: 118.

14. Jacobson AJ: Materials for Solid Oxide Fuel Cells $\uparrow$. Chemistry of Materials 2009, 22(3):660-674.

15. Zhang HM, Shimizu Y, Teraoka Y, Miura $\mathrm{N}$, Yamazoe N: Oxygen sorption and catalytic properties of La1-xSrxCo1-yFeyO3 Perovskite-type oxides. Journal of Catalysis 1990, 121(2):432-440.

16. Wang X, Chen Z, Atkinson A: Crack formation in ceramic films used in solid oxide fuel cells Journal of European Ceramic Society 2013, in press.

17. Lai BK, Xiong H, Tsuchiya M, Johnson $\mathrm{AC}$, Ramanathan S: Microstructure and Microfabrication Considerations for Self-Supported On-Chip Ultra-Thin Micro-Solid Oxide Fuel Cell Membranes. Fuel Cells 2009, 9(5):699-710.

18. Maiti A, Rajender B: Terpineol as a dispersant for tape casting yttria stabilized zirconia powder. Materials Science and Engineering: A 2002, 333(1):35-40. 